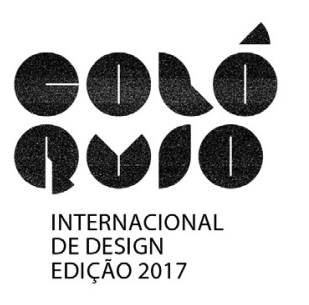

\title{
Denim resíduo sólido da indústria têxtil brasileira: ações sustentáveis sob o olhar do design.
}

\author{
Ildênia Maria Dias; \\ Cristiane Bom Conselho Sales Alvarenga; \\ Rosemary Bom Conselho Sales.
}

resumo:

O Brasil é um importante integrante do setor têxtil mundial, se destacando como produtor de fios e tecidos. Apesar da importância do setor para economia do país, diariamente são geradas toneladas de resíduos nos grandes centros têxteis. Estes resíduos são um problema para a sociedade e particularmente para as empresas que gerenciam o lixo urbano. Um tipo de tecido muito fabricado atualmente é o denim, mais tradicionalmente conhecido como índigo blue. Ele é produzido a partir do entrelaçamento de fios de algodão e parte desses fios (urdume), recebe tingimento com corante anil (índigo). Estima-se que o consumo mundial de denim seja de 3 bilhões de metros lineares por ano, sendo os maiores consumidores Estados Unidos, Europa e Japão. Juntos estes países consomem cerca de $65 \%$ da produção mundial do tecido. O Brasil produz cerca de 600 milhões de metros lineares de denim por ano. O maior problema enfrentado por essa indústria é a quantidade de efluentes industriais oriundos dos processos produtivos e de manufatura dos produtos têxtis, principalmente das fases de plantio, lavagem e de tingimento. Ser sustentável neste setor passa a ser um grande desafio, em função da dificuldade em adequar o processo produtivo, desde a obtenção da matéria-prima até o seu descarte. Uma forma de minimizar os impactos gerados pelos resíduos têxteis poderia ser a sua reutilização ou inserção na própria cadeia produtiva. Uma das missões de atuação do design é analisar e avaliar as interconexões organizacionais, estruturais, funcionais e econômicas dos sistemas produtivos, com o objetivo de favorecer a sustentabilidade global e a proteção ambiental. O presente estudo tem como objetivo levantar informações sobre o panorama atual do setor têxtil no Brasil, seus impactos, as ações sustentáveis de design para o setor e o panorama da produção do denim, tecnologias e perspectivas futuras.

\section{palavras-chave:}

Design, meio-ambiente; resíduos têxteis; denim; produção sustentável. 


\section{Panorama do setor têxtil no Brasil}

O Brasil foi um país essencialmente agrícola até os anos de 1960, época em que grande parte dos trabalhadores (cerca de 50\%) se dedicavam ao cultivo das terras, uma pequena parte à indústria $(15 \%)$ e o restante $(35 \%)$ se dedicavam a atividades de serviços. Nas décadas de 1970/1980 houve a migração dos trabalhadores do campo para os grandes centros urbanos, passando a representar $24 \%$ do total da mão de obra ativa em trabalho na indústria e 53\% no setor de serviço (ZONATTI, 2013). Em 1990 a cultura do algodão sofreu uma queda na produção, impondo um ônus à indústria têxtil, que se viu obrigada a aumentar as importações de insumos têxteis artificiais e sintéticos. Contudo, o setor adquiriu modernização nos processos produtivos, potencializou a produtividade e alavancou o setor em crise. Tais transformações, favoreceram também o setor de confecções que pôde absorver maior número de trabalhadores e oferecer tecidos com menores preços, as exportações brasileiras também se intensificaram para o Mercosul. Nos anos 2000, uma nova mentalidade sobrepôs ao sistema tradicional de produzir, surgiram as preocupações ambientais. A sociedade percebeu e reivindicou das empresas atitudes, como tratamento de água, do solo, preservação da flora, das matas, reciclagem de resíduos, dentre outros. Nas décadas seguintes, até os nossos dias, o foco voltou-se para a redução da poluição mediante instrumentos econômicos e códigos voluntários de conduta desenvolvidos por entidades sem fins lucrativos. As empresas se viram obrigadas a atrelar suas metas as causas ambientais. Atitudes proativas foram desenvolvidas para antecipar, identificar e resolver problemas ambientais, utilizando os recursos de tecnologias mais limpas em seus sistemas produtivos (KON e COAN, 2005).

O Brasil é considerado hoje o quinto maior produtor mundial de artigos têxteis, com produção de 1,8 milhões de toneladas de artigos confeccionados. É também o quinto maior produtor de algodão (fibra natural mais consumida no mundo, $60 \%$ das peças de vestuário são confeccionadas de algodão). Ocupa a sétima posição na produção de fios e tecidos planos e a terceira posição na produção de tecidos de malha. O setor gera 8 milhões de empregos diretos/indiretos e em 2014 somaram 1,7 milhão de postos de trabalho. Sendo $16,9 \%$ do total de trabalhadores alocados na produção industrial dos quais, 75\% é mão-de-obra feminina (ABIT, 2017). É também o maior mercado de vestuário da América do Sul seguido pelo México. O Sudeste é a principal região produtora e concentra os maiores mercados consumidores, e centros de distribuição de atacado e varejo. As regiões da grande São Paulo, Americana, Araraquara e Campinas são um importante polo produtor e empregador, respondendo por $29,8 \%$ de tudo o que é produzido pelo setor (SINDIFIATEC, 2017).

A indústria têxtil e de confecção é amparada por quatro setores que compõem sua cadeia produtiva: a indústria química, que fornece as fibras fabricadas pelo homem e insumos para tinturaria e acabamento; a indústria agropecuária que fornece fibras naturais, vegetais e animais; a indústria têxtil (inclui fiação, malharia e tecelagem) e que a partir das matérias-primas produz os tecidos; e a indústria de confecção que transforma os tecidos em vestimentas e correlatos (SILVA, 2009).

Em 2014 a cadeia têxtil e de confecção produziu cerca de US\$ 57,2 bilhões, o que equivale a $5,6 \%$ do valor total da produção da indústria brasileira de transformação (IEMI, 2014). Em 2014 o país passou a importar mais produtos têxteis e confeccionados (vindos principalmente da Ásia), passando de 12,1\% em 2013 para 14\% (Tabela 1). A projeção é de que em 2020, 20\% do vestuário que circulará no Brasil seja importado (ZONATTI, 2016).

Tabela 1 - Participação das importações de vestuário no mercado nacional

\begin{tabular}{c|c|c}
\hline \multicolumn{3}{|c}{ Participação das importações de vestuário } \\
\hline Ano & $\begin{array}{c}\text { Importação (milhões } \\
\text { de peças) }\end{array}$ & $\begin{array}{c}\text { Participação dos } \\
\text { importados (\%) }\end{array}$ \\
\hline 2009 & 273 & 4,4 \\
\hline 2010 & 405 & 6,0 \\
\hline 2011 & 640 & 9,3 \\
\hline 2012 & 748 & 10,9 \\
\hline 2013 & 844 & 12,1 \\
\hline 2014 & 1001 & 14,0 \\
\hline $2020 *$ & \multicolumn{2}{c}{20,0} \\
\hline \multicolumn{3}{c}{}
\end{tabular}

Fonte: Adaptado do IEMI, (2014) 
Um tipo de tecido muito fabricado no Brasil é o denim, tradicionalmente conhecido como índigo blue ou tecido jeans, sua produção anual gira em torno de 600 milhões de metros lineares (FIGUEIREDO e CAVALCANTE, 2010). Segundo levantamento da International Textile Manufactures Federation - ITMF (2011), o Brasil está à frente de países como Índia, China e Coréia do Sul no setor de fiação convencional ou na tecelagem que utiliza o fio Open End (fio mais rústico que o convencional) como matéria-prima, da mesma forma para os grandes fabricantes de denim no segmento de jeanswear (ABIT, 2012). Atualmente cerca de 15 empresas brasileiras produzem este tipo de tecido, estima-se que até 2023 ele seja um dos principais segmentos de tecelagem para o consumo em vestuário (ABDI, 2010).

\section{Produção têxtil de denim}

A história do denim surgiu por volta de 1850, com a corrida do ouro dos Estados Unidos, onde o trabalho pesado dos garimpeiros nas montanhas exigia vestimentas resistentes. Para atender a esta demanda, Levi Strauss (comerciante), criou uma calça, com modelagem própria, reforçadas com lona para os trabalhadores. A partir dessa modelagem ele aprimorou o processo e substituiu a lona por um tecido rustico de algodão muito fabricado na França. Da evolução deste tipo de vestimenta, mais tarde surgiu o tecido que ficou conhecido mundialmente como denim ou Índigo blue.

Por seu estilo despojado, a roupa fabricada com denim, conquistou notoriedade a partir de personalidades do cinema americano como James Dean e Marlon Brando na década de 1960. A partir do início do século XX, o denim foi o tecido mais fabricado para confecção de calças Jeans e elas se transforou em símbolo de juventude, rebeldia e inovação. Sendo a vestimenta preferida dos jovens considerada como a peça mais versátil e democrática do guarda-roupa de qualquer pessoa, de qualquer idade, sexo, ou classe social. Atualmente existe uma infinidade de roupas, fabricadas com o tecido.

O Brasil é um dos principais produtores mundial de denim, com capacidade instalada de produção acima de 600 milhões de metros lineares por ano (FIGUEIREDO e CAVALCANTE, 2010). Existem aproximadamente 15 empresas que produzem os tecidos denim de forma integrada, ou seja, que têm o processo completo de tecelagem. De acordo com estudos de prospecção setorial, para 2023, o jeans é apontado como um dos principais segmentos de consumo de vestuário. Portanto, as empresas terão que se adequar aos futuros requisitos esperados, não só ambientais, mas inclui-se a integração com tecnologias de comunicação, monitoramento de funções biológicas, proteção e conforto (ABDI, 2010). No processo de fabricação do denim utiliza-se dois tipos de fios (Figura 1a), o urdume normalmente com ligamento em sarja, e a trama (Figura 1b) fio 100\% algodão cru.

Figura 1. Identificação do fio para fabricação do denim

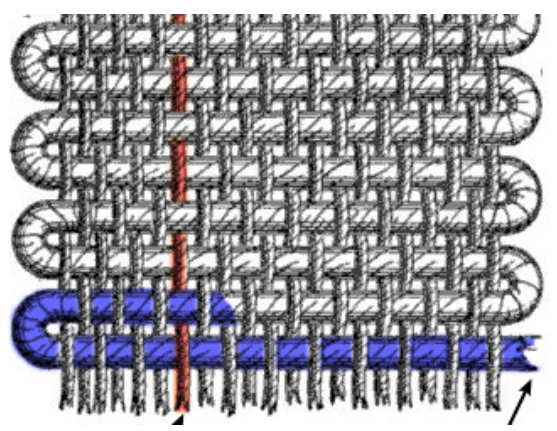

(a) urdume

(b) trama

Fonte: https://de.wikipedia.org/wiki/Weben

O nome índigo blue vem da planta indiana chamada índigus, de onde se extrai da raiz o corante azul para o tingimento (Figura 2a). O corante índigo não tem muita afinidade com o algodão, por isso, o tingimento fica apenas na superfície dos fios de urdume, formando em cada fio um anel azul intenso com o núcleo branco (Figura 2b). A solidez do tecido é baixa ao atrito o que resulta na perda da camada superficial de fibras e a cor azul perde sua intensidade ficando suavizada. Após o 
tingimento, os fios são trabalhados em teares onde é fabricado o tecido denim e estes, são colocados em rolos para serem comercializados (FIGUEIREDO; CAVALCANTE, 2010).

Figura 2 - Corante índigo

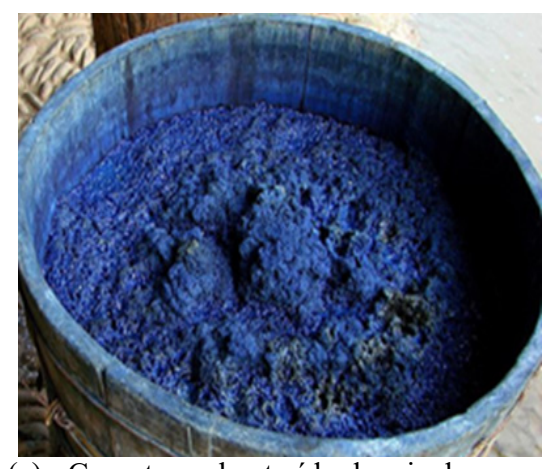

(a) Corante azul extraído da raiz do índigo

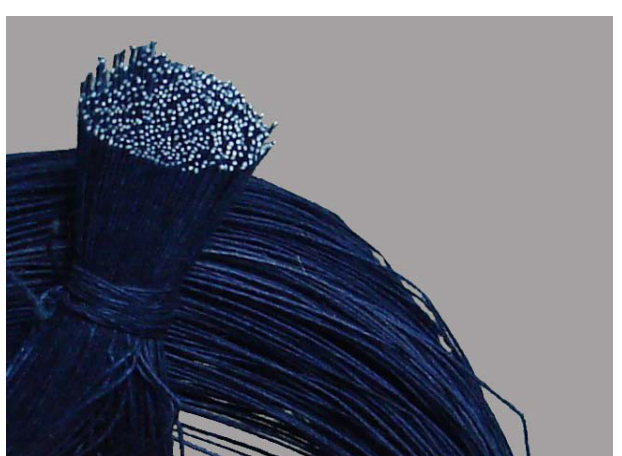

(b) Fio tingido com corante índigo, mantendo núcleo branco

Fonte: Figueiredo; Cavalcante, (2010).

O tecido denim passou por diferentes transformações ao longo dos anos ditando moda e fazendo história. Atualmente novos materiais estão sendo introduzidos em sua estrutura tornando-o ainda mais atraente para a indústria de confecção, com novas possibilidades e tonalidades para o produto. $\mathrm{O}$ tecido continua a ser o centro da moda e dita padrões de comportamento em todo o mundo em função da sua versatilidade, contudo sua identidade ainda se firma nos vários modelos de calças jeans (Figura 3).

Figura 3 - Versatilidade do jeans

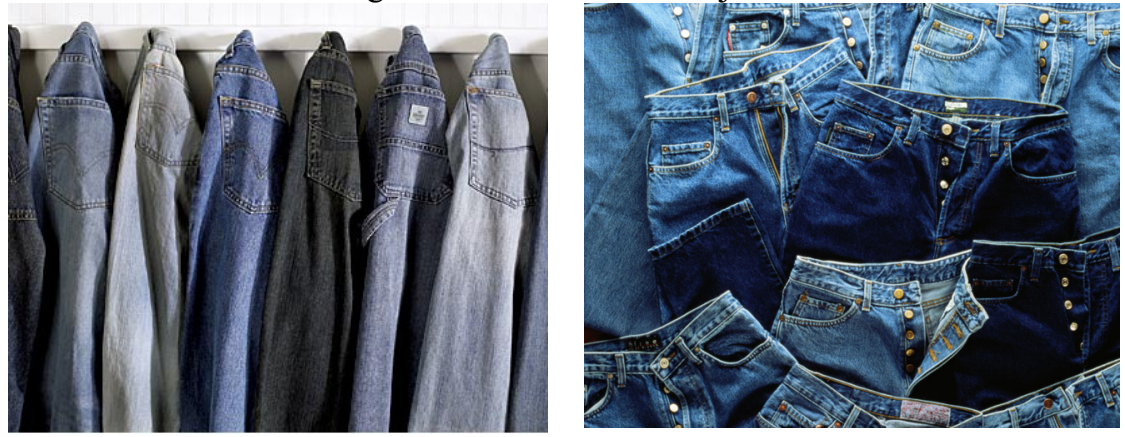

Fonte: $<$ http://www.business.org.br $>$

Não resta dúvidas de que o tecido se estabeleceu no mercado mundial, seu consumo gira em torno de 3,4 bilhões de metros lineares por ano. Os principais consumidores são os Estados Unidos, a Europa e o Japão, juntos eles representam mais de $65 \%$ do consumo mundial (TAVARES 2011).

Esse produto de desejo global, tem um custo alto em seus processos produtivos e para o meio ambiente. Segundo o Instituto Ecotece, o denim é feito majoritariamente de algodão, cultura que recebe $25 \%$ dos agrotóxicos consumidos no mundo em suas plantações. Estima-se que para um quilo de tecido jeans são necessários cerca de 11.800 litros de água. Outro fator que chama a atenção é o tingimento feito com corantes derivados do petróleo, o corante natural (índigo) está perdendo lugar para o anil sintético e outros. Após ser colocado em tonéis de corante o tecido sofre tratamentos de desgaste por rajadas de substâncias químicas, como amônia e soda cáustica, que, além de prejudiciais à saúde humana, são altamente poluentes para os balanceais aquáticos. Somam-se a isso, os grandes volumes de água e de energia que são gastos, além de toneladas de $\mathrm{CO}_{2}$ emitidas ao longo do ciclo de vida do produto. Para a produção mundial de tecido denim em tom azul médio, seriam consumidos 5,2 trilhões de litros d'água. Este volume, de acordo com a Agência Nacional de Águas, equivalente a 11 horas da vazão média do Rio Amazonas no $\operatorname{mar}\left(133.000 \mathrm{~m}^{3} / \mathrm{s}\right)$.

As águas do Rio Capibaribe, na cidade de Toritama em Pernambuco, durante vários anos tiveram suas águas contaminada com o despejo de lavagens de jeans de 56 lavanderias da cidade, hoje, a mando do Ministério Público, as empresas são obrigadas a tratar a água de tingimento antes de lançá- 
las no rio (TAVARES, 2011; SOUZA, 2008; FOLADORI, 2008). Mas esta realidade está sendo progressivamente melhorada graças ao envolvimento do governo e das empresas na busca por processos menos agressivos.

\section{Impactos ambientais no processo de produção}

A indústria têxtil é uma das indústrias que mais contaminam o meio ambiente, gerando grandes quantidades de resíduos sólidos. O termo resíduo sólido, normalmente é utilizado como sinônimo de lixo, segundo o dicionário da língua portuguesa (BUENO, 2001), a palavra lixo é derivada do latim lix e significa, de modo geral, tudo que se joga fora, no entanto, o significado de resíduo vem do latim residuum, definido como o que resta ou o que sobra. A Associação Brasileira de Normas Técnicas NBR 10.004 - ABNT (2004) define resíduos sólidos como:

"Resíduos nos estados sólido e semissólido, que resultam de atividades da comunidade de
origem: industrial, doméstica, hospitalar, comercial, agrícola, de serviços e de varrição. Ficam
incluídos nesta definição os Iodos provenientes de sistemas de tratamento de água, aqueles
gerados em equipamentos e instalações de controle de poluição, bem como determinados
líquidos cujas particularidades tornem inviável seu lançamento na rede pública de esgotos ou
corpos d'água, ou exijam para isso soluções técnicas e economicamente inviáveis, em face da
melhor tecnologia disponível."

De qualquer forma, resíduo, sob a ética da economia, é todo material entendido como subproduto de um sistema produtivo e dotado de valor econômico, com a oportunidade de reutilização em linhas de produção (CALDERONI, 2003). Nesse sentido, normas e leis tentam equacionar a forma mais correta de lidar com os resíduos. A NBR 10.004 - ABNT (2004), busca facilitar o gerenciamento dos resíduos sólidos, e classifica-os como facilmente degradáveis, moderadamente degradáveis, dificilmente degradáveis e não degradáveis. Com relação à contaminação do meio ambiente, os resíduos são classificados mediante a identificação do processo ou atividade que lhes deu origem como apresentados na Figura 6.

Figura 6 - Classificação dos resíduos sólidos segundo a origem

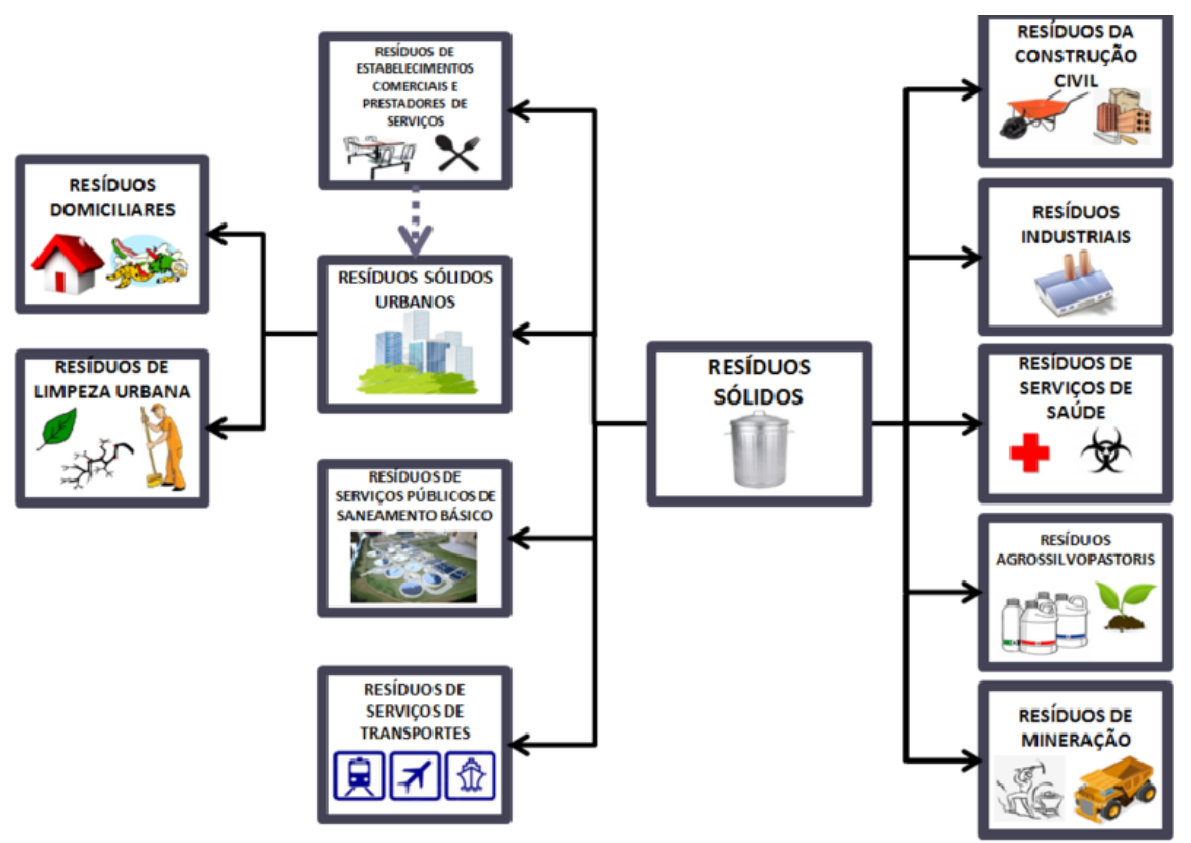

Fonte: RQ Ambiental < http://rqambiental.blogspot.com.br/2015/12/residuos-solidos.html>

Além disso é necessário a avaliação de seus constituintes, das características e a comparação destes com listagens de resíduos e substâncias cujo impacto à saúde e ao meio ambiente são considerados significativos. A periculosidade de um resíduo é medida segundo as características 
apresentadas em função de suas propriedades físicas, químicas ou infectocontagiosas (Figura 7), apresentando risco à saúde pública, provocando mortalidade e incidência de doenças, e riscos ao meio ambiente, quando o resíduo for gerenciado de forma inadequada (ABNT 2004).

Figura 7 - Resíduos sólidos de acordo com NBR 10004 ABNT (2004)

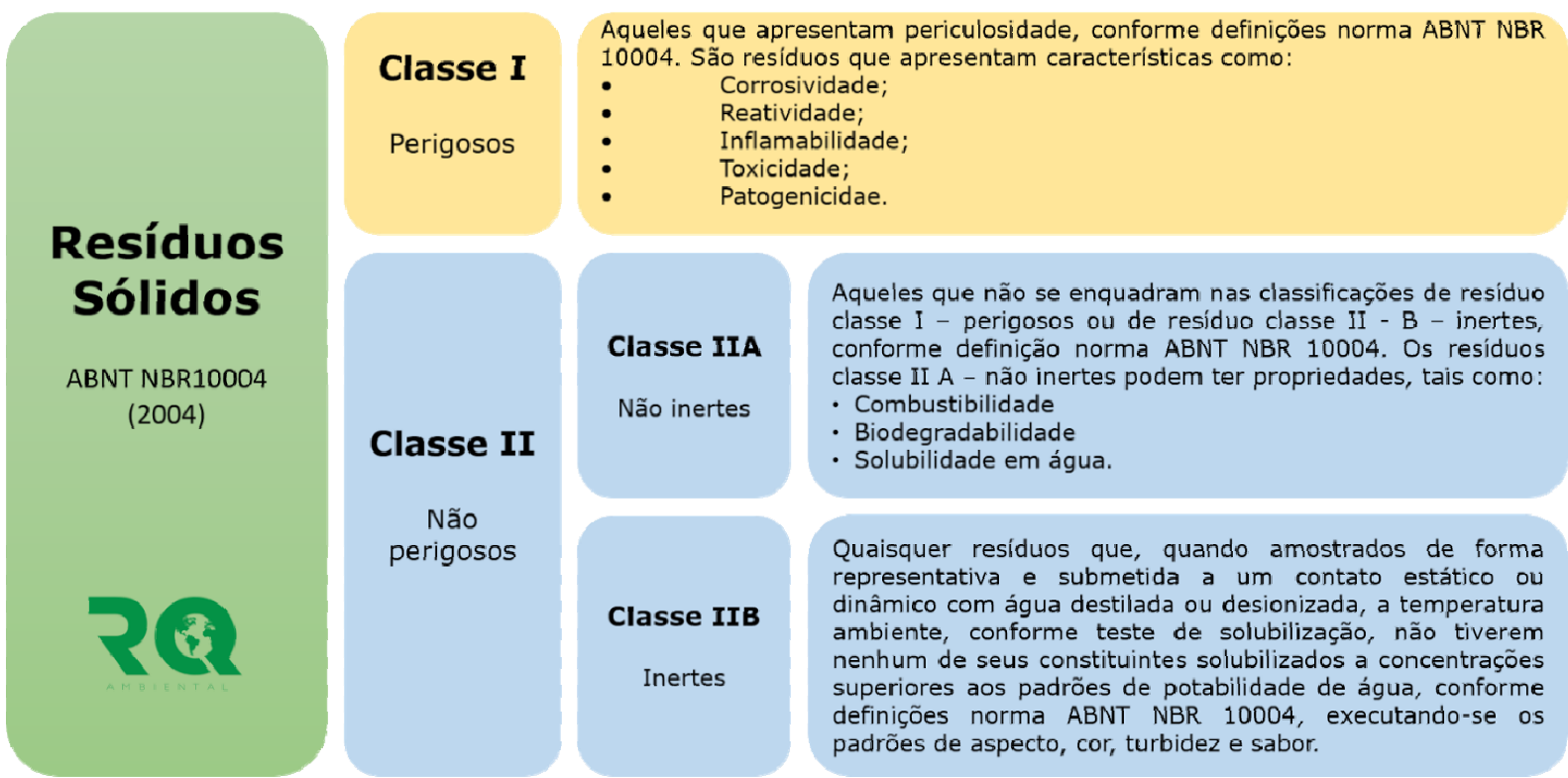

Fonte: RQ Ambiental < http://rqambiental.blogspot.com.br/2015/12/residuos-solidos.html>

A Lei que regula a Política Nacional de Resíduos Sólidos - PNRS, sancionada em agosto de 2010, Lei 12.305 (BRASIL, 2010), trata das diretrizes relativas a gestão integrada e ao gerenciamento de resíduos sólidos e as responsabilidades das empresas geradoras, abrangendo o poder público e os demais instrumentos econômicos aplicáveis. Sobre tal lei pode-se ressaltar a responsabilidade sobre os resíduos que se estendem aos fabricantes, importadores e comerciantes e demanda que os envolvidos promovam a reciclabilidade, a logística reversa e a gestão adequada desses resíduos (RIOS, 2012).

A PNRS estabelece no Brasil as bases para a gestão do lixo sólido urbano, a partir do princípio da logística reversa, e compartilha a responsabilidade sobre a recuperação de materiais pós-consumo, promovendo o seu retorno a novos ciclos de vida como insumo para a fabricação de novos produtos. Deste modo, as indústrias, comerciantes, distribuidores e envolvidos no processo, devem programar sistemas de logística reversa, CEMPRE (2011). A mesma lei, promove mudanças no cenário desses resíduos, tendo como princípio a responsabilidade compartilhada entre governo, empresas e população. Essa lei incentiva o retorno dos produtos pós-consumo às indústrias e obriga o poder público a realizar planos para o gerenciamento do lixo.

Uma nova lei está sendo discutida atualmente no Congresso Nacional e afeta o setor têxtil e de confecção principalmente em relação ao possível abastecimento de lenha e a localização de novas empresas em função da presença de cursos de água. A indústria têxtil foi responsável em 2010 pelo consumo de 300 mil toneladas de lenha. A lenha obtida de florestas plantadas e certificadas ainda é considerada uma importante fonte de energia para alimentação de caldeiras e representa $7 \%$ do consumo de fontes energéticas para o setor têxtil (EPE, 2010).

O estado de Minas Gerais instituiu sua Política Estadual dos Resíduos Sólidos (PERS) a partir da Lei $\mathrm{n}^{\mathrm{o}} 18.031$, de 12 de janeiro de 2009, com o objetivo de orientar os municípios mineiros na gestão adequada dos resíduos sólidos urbanos. A lei determina que os municípios, as empresas fabricantes, os importadores, os distribuidores, os comerciantes e os prestadores de serviços ficam obrigados a colaborar com o Plano de Gestão Integrada de Resíduos Sólidos, promovendo formas de acondicionamento, transporte, armazenamento e tratamento dos resíduos sólidos especiais, bem como a disposição final ambientalmente adequada; a manutenção de centros de coleta; e desenvolvimento de estudos e pesquisas orientadas a redução, processamento e gerenciamento dos resíduos (MINAS GERAIS, 2009). 
No município de Belo Horizonte a gestão de resíduos sólidos é de responsabilidade da Superintendência de Limpeza Urbana (SLU), criada em 1973 sob a forma jurídica de autarquia municipal, que tem como objetivo coordenar, planejar, executar e fiscalizar os serviços de limpeza pública de Belo Horizonte (RIOS, 2012).

\section{Foco em sustentabilidade}

Sabe-se que a procura por um desenvolvimento sustentável não é um pensamento atual. Medidas governamentais continuam a ser tomadas para regulamentar as responsabilidades dos envolvidos. Nos últimos anos, estas questões têm fortalecido seus valores e atribuído as indústrias, novos desafios para atender a demanda de um mercado cada vez mais exigente. Isso se deve, principalmente a forma como os produtos e serviços são produzidos, utilizados e descartados e como eles afetam o meio ambiente. Outro imperativo é o surgimento de novos movimentos de regulação ambiental em todo o mundo.

De igual forma, as indústrias têm se interessado e cobrado das grandes organizações parceiras práticas e metodologias cujo objetivo é manter o equilíbrio entre processos produtivos e preservação ambiental, certificações com reconhecimento internacional, controle da redução dos recursos naturais, dentre outras, (OLIVEIRA; SERRA, 2010). O desenvolvimento sustentável busca o equilíbrio entre as dimensões ambiental, sociocultural e econômica, sendo definidas como metas ações ambientalmente responsáveis, socialmente justas, economicamente viáveis. São ações sustentáveis que estabelecem objetivos multidimensionais (Triple Bottom Line) ao considerar aspectos essenciais como:

- Dimensão econômica: a organização deve ser capaz de produzir produtos e serviços continuamente;

- Dimensão ambiental: a empresa deve reduzir as agressões ao meio ambiente, promover a melhoria das condições ambientais e evitar o desperdício;

- Dimensão social: a empresa deve avaliar o impacto do negócio no sistema social no qual ela atua.

São ações de conscientização realizadas por meio de mudanças e a prática da aplicação dos 3Rs (reduzir, reutilizar, reciclar). Redução da quantidade de matéria-prima e energia, reduzir ou eliminar do uso de materiais tóxicos, reduzir o volume dos resíduos e emissões. Reutilizar é uma forma de prolongar o ciclo de vida de um produto, inserindo-o na geração de novos produtos. Reciclar os produtos químicos para realimentar o sistema, racionalizar os insumos como água e agentes químicos, dentre outros (MASSOTE, 2010; DEBASTIANI e MACHADO, 2012).

Segundo El-Haggar, (2007) a regra dos 3Rs, pode ser potencializada para regra dos 7Rs, onde o quarto R enfatiza a recuperação de matérias-primas através do tratamento sustentável do lixo. Os outros dois Rs correspondem a repensar e renovar, que implicam em uma revisão do sistema de produção, distribuição e descarte, envolvendo inovações tecnológicas à solução dos problemas. $\mathrm{O}$ último $\mathrm{R}$ diz respeito a Regulação, sem a qual se torna difícil a implementação de qualquer outra das regras. É muito importante adicionar a Regulação ao sistema para incentivar a implementação dos demais princípios da regra dos Rs, promovendo a produção mais limpa e incorporando os custos ambientais nos custos impostos pelos governos à produção.

Ao considerar, o caso da indústria têxtil e de vestuário, a utilização destes conceitos pode contribuir para obtenção melhores lucros por parte das empresas ao eliminar custos associados aos seus diferentes processos de produção. Com isso, as empresas que exploram a capacidade produtiva dos recursos naturais, são movidas a atender as regras normativas estabelecidas por esses organismos sob condição de colocar em risco todo o processo produtivo.

Segundo a Agência Brasileira de Desenvolvimento Industrial ABDI (2010), o texto para a Visão de Futuro do setor têxtil no Brasil que resultou da construção coletiva de uma pesquisa realizada pela empresa ficou assim redigido:

"Ser competitiva globalmente e exportadora de destaque, possuindo como diferencial competitivo o uso criativo dos valores culturais, a utilização ética e sustentável da diversidade de materiais, de recursos naturais e humanos, com interação com outros setores produtivos, incorporando tecnologia de ponta para agilizar seus processos desde a concepção ao descarte, 
com produtos customizados, funcionais e inovadores, que despertem a emoção do consumidor e atendam o custo-benefício positivo para os diferentes segmentos de consumo".

Informações da Accenture Sustainability Services mostram que, em 2014, a cidade de Nova York lançou um estudo sobre sustentabilidade corporativa. O estudo mostrou que $93 \%$ dos executivos entrevistados, veem a sustentabilidade como fundamental para o sucesso da empresa e acreditam que uma nova era esteja iniciando. A maior parte dos entrevistados, $80 \%$, preveem um "ponto de inflexão" dentro de 15 anos onde haverá um momento em que a sustentabilidade será totalmente incorporada às estratégias de negócio da maioria das empresas em nível global (ROCHA, 2014).

Segundo notícias da BBC Internacional, em dezembro de 2015 a conferência internacional, realizada em Paris, sobre o clima - COP 21, discutiu as metas para se chegar a um acordo global sobre as mudanças climáticas. $\mathrm{O}$ ponto central discutido na conferência foi os países se comprometerem manter o aquecimento global abaixo de $2^{\circ} \mathrm{C}$ a partir de 2020. Os 195 países membros da Convenção do Clima da ONU e a União Europeia, ratificaram um documento e pela primeira vez todos os países participantes se comprometeram a reduzir as emissões de carbono e conter os efeitos do aquecimento global. Nessa trajetória, novos desafios surgem a cada dia e fez-se necessário o estabelecimento de métodos que possibilitem às empresas avaliar as consequências ambientais das decisões tomadas em relação aos seus processos e produtos.

O desafio é minimizar os impactos causados por produtos que usados rotineiramente, geram demandas, mas como consequência geram oportunidades notadamente visualizada no desafio de criar novos produtos a partir de resíduos sólidos derivados da indústria têxtil do Brasil. O retrato real do impacto da indústria de denim só foi conhecido em 2006, quando a Levis Strauss \& Co. divulgou resultados da avaliação de seu ciclo de vida com o que era gasto na fabricação de um exemplar do jeans. $400.000 \mathrm{~kW}$ de energia, $32 \mathrm{~kg}$ de dióxido de carbono expelidos, além de galões de água. Conforme divulgado pela própria marca, é como manter uma mangueira ligada por 106 minutos, dirigir por $125.502 \mathrm{~km}$ e manter ligado um computador por 556 horas (FIGUEIREDO; CAVALCANTE, 2010).

Hoje a atuação do design vem se expandido e uma de suas principais metas é analisar e avaliar as interconexões organizacionais, estruturais, funcionais, expressivas e econômicas, com o objetivo de favorecer a sustentabilidade global e a proteção ambiental, seja para gerar valor para a empresa ou contribuir para o seu melhor desempenho e com uma preocupação ambiental. Nesse sentido, ações sustentáveis sob o olhar do design podem ser pensadas para a não geração de resíduos no contexto da indústria têxtil. Nesse sentido, considera-se que o design possa contribuir com ações de minimização ambiental, no que se refere ao desafio da sustentabilidade. Tendências mundiais estimulam os profissionais a repensar seus conceitos tradicionais e alertam para necessidade de desenvolver produtos sob o ponto de vista do design para sustentabilidade.

De acordo com a ABDI (2010), a funcionalização de produtos têxteis acontece através da modificação de superfícies de fibras, fios, tecidos ou da combinação de materiais. Em muitos casos, a funcionalização torna os tecidos aptos para novas aplicações como para fabricar roupas usadas ou roupas de proteção, bem como têxteis automotivos, para a construção e indústrias entre outras inovações. Pode-se seguir várias linhas para um resultado cada vez mais sustentável favorecendo o meio ambiente como por exemplo:

- Métodos de design para eficiência em materiais e desenvolvimento de produtos;

- Novas funcionalidades para materiais;

- Processos verdes para aumento da funcionalização;

- Processos de funcionalização mais versáteis, flexíveis e apropriados à produção de pequenas séries;

- Produtos auxiliares de base biológica em aplicações BAT (Best Available Techniques) e técnicas emergentes que minimizem o impacto ambiental dos processos têxteis;

- Bioprocessos que aperfeiçoem aplicações tecnológicas de novas fibras e processos sustentáveis que adotem o princípio da produção mais limpa;

- Materiais com propriedades desenvolvidas para biomedicinais, têxteis e aplicações técnicas. 


\section{Ações sustentáveis sob o olhar do design}

Partindo do princípio proposto por Kathryn Best, no livro Design management: managing design strategy, process and implementation - Gestão estratégica de projeto, processo e implementação pelo design. A estratégia de design define como a organização pretende utilizar o design, e como o processo de design pode melhor servir às suas necessidades operacionais. Tais ações podem ser alcançadas quando operações acontecem em diferentes níveis da empresa e são mobilizadas como forma de pensar o design (BEST, 2006). Assim, o design é capaz de gerar valor para a empresa e contribuir com ações para o seu desempenho e mensuração, desde que esses valores sejam representativos e que as estratégias estejam alinhadas às estratégias da empresa. Esta estratégia está diretamente ligada ao conjunto das ações de gestão empresarial, gestão de design e dos princípios do design para sustentabilidade. De acordo com Manzini e Vezzoli, (2008) entende-se a expressão design para a sustentabilidade, como o ato de projetar produtos, serviços e sistemas com um baixo impacto ambiental e uma alta qualidade social.

O design com seu papel conciliador e transversal, neste contexto, contribui para a produção de produtos e serviços com uma preocupação social, e com foco na sustentabilidade, proporcionando ao consumidor oportunidade de avaliar, sob um novo ângulo, os produtos de sua escolha (KRUCKEN e TRUSEN, 2013). Tais aspectos deram início a práticas e metodologias cujos objetivo é manter o equilíbrio entre processos produtivos e preservação ambiental sob o olhar do design e sob suas práticas metodológicas como: Gestão Estratégica em design, Ecoeficiência, Análise do Ciclo de Vida, Responsabilidade Socioambiental, Produção + Limpa, dentre outros. Nesta visão, na indústria têxtil, as ações sob o olhar do design, podem ser repensadas dentro de diferentes alternativas sustentáveis onde as ações da empresa sejam direcionadas para a redução dos impactos negativos do ciclo de vida dos produtos, da extração da matéria-prima até a disposição final do produto, e que o foco seja a minimização ou a eliminação de resíduos e formas mais efetivas de combater a degradação do meio ambiente e prolongar o ciclo de vida dos produtos (LEITE, 2003).

Segundo uma pesquisa realizada pela ABDI 2010, o design assumirá a responsabilidade de humanizar meios e recursos tecnológicos. Pode-se esperar um redirecionamento de produtos orientado cada vez mais por questões sociais, ambientais e econômicas, consolidando o design sustentável, que deixa de ser uma atividade de produção para adotar um papel estratégico. Ainda de acordo com a mesma pesquisa, a liderança do design sustentável na coordenação sociotécnica da fabricação de produtos terá importância para o setor têxtil no Brasil. Reuso e disposição foram conceitos incorporados na relação entre o design sustentável e o consumo consciente.

No que se refere à sustentabilidade, o ecodesign ou design sustentável, significa projetar produtos que propiciem o bem-estar social com o mínimo desperdício e prejuízo para a natureza. $\mathrm{O}$ ecodesign pode introduzir uma estratégia de início de processo. A responsabilidade da empresa fabricante começa na escolha das matérias-primas, passando pela gestão dos processos de projeto, fabricação, embalagem, transporte, instalação, utilização, durabilidade, reaproveitamento incluindo o tratamento de resíduos. Atualmente designers têm reciclado sobras de tecidos como o denim, que recebem novo design, interpretação e modelagem. Algumas empresas de beneficiamento têm introduzido enzimas, produtos biodegradáveis, em cada etapa do processo que envolve a fabricação do desse tecido, inclusive o desbotamento. Já os fabricantes têm lançado produtos que respondem com maior velocidade aos processos de lavagem, reduzindo ao mínimo a exigência de tais processos bem como a utilização de produtos químicos (FIGUEIREDO; CAVALCANTE, 2010).

Pode-se citar alguns exemplos de empresas que elaboram seus produtos livres de composições químicas para criar produtos ecologicamente corretos:

- Clariant: produto Advanced Denim, em que a exigência de utilização de água no processo de lavagem apresenta uma economia de $60 \%$;

- Jeanologia: lançou uma máquina de alvejamento que utiliza ozônio e não água em seus processos. Essa tecnologia chamada também de G2 produz várias tonalidades e nuances de denim.

- Buildinggreen.com: utilizam resíduos de denim para criar produtos de isolamento térmico.

De acordo com a ABIT 2012, a partir da consolidação de metodologias aplicáveis ao setor têxtil, com o apoio de serviços especializados e capacitação adequada, poderão ser disseminadas 
informações para atuação sustentável integrada dos diversos atores da cadeia, tais como agricultores, produtores, trabalhadores e designers. Munidos de informações integradas, todos poderão contribuir de modo consciente para a minimização dos impactos indesejáveis ao meio ambiente, promovendo mudanças expressivas no patamar de sustentabilidade.

Diferentes países tentam implementar políticas de reaproveitamento dos resíduos têxteis como é o caso da Alemanha. Eles utilizam o sistema de reuso e reciclagem têxtil com base nos 3Rs, gerenciando seus resíduos mediante logística reversa, proteção ao meio ambiente e sustentabilidade (MUHAMMAD, 2013).

No Reino Unido, observa-se que a reciclagem de têxteis ainda é pouco estudada, estima-se que mais de 1 milhão de toneladas de resíduos são descartados a cada ano, sendo a maior parte provenientes de fontes domésticas (WASTE ON LINE, 2017).

Em Portugal, empresas atuam timidamente no setor de reuso e reciclagem de artigos têxteis. No entanto, acredita-se que esse panorama de reciclagem de têxteis e vestuário deverá mudar no país em função da Legislação da União Europeia que aponta os têxteis como uma "corrente de resíduos prioritária". A legislação na forma da revisão da Diretiva de Resíduos, está em vigor desde dezembro de 2008 e tem como objetivo tornar mais fácil para os cidadãos e empresas o ato de reciclar.

Segundo a Camara di Commercio Prato (CCP), o caminho encontrado foi a certificação para as empresas que conseguirem diminuir ou eliminar dos seus processos de produção as emissões de dióxido de carbono $\left(\mathrm{CO}_{2}\right)$. Os critérios para certificação é que o produto têxtil utilize pelo menos $70 \%$ de matérias-primas recicladas, e o produto ser produzido dentro do distrito de Prato na Itália (CCP, 2017).

Nos Estados Unidos, existe uma organização não-governamental sem fins lucrativos, denominado Council for Textile Recycling ou Conselho para a Reciclagem de Produtos Têxteis, que busca educar a população sobre a importância da reciclagem de têxteis. A conscientização parte do princípio de que no país, a cada ano, são descartados $31,75 \mathrm{~kg}$ de resíduos por pessoa, provenientes de vestuário, calçados e têxteis, que ocupam cerca de $5 \%$ dos aterros. A ideia é eliminar $85 \%$ dos resíduos têxteis descartados pós-uso, o que corresponde a 25 bilhões de quilos de roupas, calçados e resíduos têxteis a cada ano (COULTURE MAGAZINE, 2017).

Uma exploração recente sobre ações empreendidas por pequenas, médias e grandes empresas têxteis nacionais foi realizada pelo Instituto de Prospecção Tecnológica e Mercadológica do Senai IPTM e pelo Centro de Tecnologia da Indústria Química e Têxtil - CETIQT. As empresas foram selecionadas em três regiões brasileiras. Os resultados mostram que, houve melhoria nos processos relacionados aos impactos de medição, cumprimento de regulamentos internacionais e realização de programas ambientais para a comunidade. A grande maioria das empresas cumpre os regulamentos internacionais e apresentaram iniciativas educacionais ou projeto de melhoria ambiental para suas comunidades locais (ABIT, 2012).

As empresas de pequeno porte tendem a se concentrar no desenvolvimento de novos produtos com atributos sustentáveis. Esses produtos fazem uso de matérias-primas recicladas, de produtos de florestas geridas de forma sustentável ou de corantes e pigmentos extraídos da flora brasileira. As atividades inovadoras estão focadas em ações de incorporação de insumos com apelo ecológico aos produtos.

Recentemente a Google ${ }^{1}$ se associou com a marca Levis em um projeto para desenvolver um produto inteligente a partir do denim. A ideia é colocar pequenos fios condutores mesclados entre aos fios do tecido que vão receber informações que serão transmitidas a um microcomputador (não maior que um botão) para serem processadas. Estes dados chegarão a dispositivos portáteis como smartphones ou tablets via transmissão wireless. A ideia é criar uma roupa tecnológica que não chame atenção pela inovação, mas sim por seu design e estilo.

O Sindicato das Indústrias de Fiação e Tecelagem do Estado de São Paulo, com o apoio da ABIT criou em 2011, o Prêmio Sinditêxtil Gestão Ambiental. O propósito do prêmio é incentivar as empresas que apresentam resultados positivos no desenvolvimento de projetos ambientais. As empresas vencedoras investem em pesquisas e equipamentos e, após alguns anos, conseguem neutralizar, deixar de emitir cerca de três mil toneladas de $\mathrm{CO}_{2}$ por ano. Trata-se de uma das iniciativas mais bem-sucedidas na área ambiental do setor têxtil.

\footnotetext{
${ }^{1}$ http://www.vix.com/pt/bbr/658/calcas-jeans-inteligente-sera-o-futuro-da-moda-google-e-levis-se-juntam
} 
Na linha dos lançamentos sustentáveis, a Vicunha Têxtil ${ }^{2}$, líder mundial na produção de índigos e brins, traz o primeiro denim que incorpora nanotecnologia em uma emulsão que contém Aloe Vera. Este princípio ativo melhora as propriedades do tecido, potencializando a suavidade e o bem-estar durante o uso. A mesma indústria se uniu à Nilit ${ }^{\circledR}$ Fibers, empresa especializada na produção de fios Nylon, para a criação de tecidos inteligentes, com funcionalidades que proporcionam bem-estar. A tecnologia presente nas fibras garante que as propriedades especiais permaneçam efetivas durante a vida da peça, não ocorrendo diminuição do efeito mesmo após sucessivas lavagens.

\section{Considerações finais}

A minimização ou a eliminação de resíduos, da extração da matéria-prima até a disposição final do produto, torna mais efetiva a forma de combater a degradação do meio ambiente do setor têxtil. Nesse sentido, o design pode, em nível estratégico, adequar as expectativas do mercado consumidor à capacidade produtiva empresarial como um todo. As ações empresariais podem ser repensadas dentro de diferentes alternativas sustentáveis a partir da consolidação de metodologias como a Gestão Estratégica em design, Ecoeficiência, Análise do Ciclo de Vida, Responsabilidade Socioambiental, Produção + Limpa, dentre outros. Com o apoio de serviços especializados e capacitação adequada, poderão ser disseminadas informações para atuação sustentável integrada dos diversos atores da cadeia com propostas estratégica para direcionar as empresas e/ou organizações ao crescimento e evolução permanente. O design com seu papel conciliador e transversal também contribui para a produção de produtos e serviços com preocupação social, buscando implementar políticas de reaproveitamento dos resíduos têxteis. Embora essa atividade seja uma contribuição importante, no Brasil, a preocupação com os descartes desses resíduos ainda é incipiente e existe carência de mecanismos facilitadores para os processos de reutilização e reciclagem têxteis.

\section{Denim`s solid waste: Designing sustainable actions in the brazilian textile industry}

\section{Abstract:}

Brazil is an important member of the textile sector worldwide, mainly by the production of yarns and fabrics. Despite the relevance of the sector for the country's economy, textile centers daily receive tons of waste. These residues are a problem for society and especially for companies that manage the urban waste. Denim is a fabric much manufactured today, more traditionally known as indigo blue. The production takes place from the interweaving of cotton yarns and part of these yarns (urdume), receives dyeing with indigo dye. The estimated global consumption of this fabric is 3 billion linear meters per year, with the largest consumers in the United States, Europe and Japan. Together these countries consume about $65 \%$ of the world's tissue production. Brazil produces about 600 million linear meters per year of denim. The biggest problem faced by this industry is the large amount of effluents generated in the production and manufacturing processes of the textile products (mostly planting, washing and dyeing phases). Being sustainable in this sector is a great challenge, due to the difficulty in adapting the production process, from obtaining the raw material to its disposal. The reuse or insertion of textile waste in the production chain could reduce environmental impacts. Designer has to analyze and evaluate the organizational, structural, functional and economic interconnections of production systems, to foment global sustainability and environmental protection. The present study aims to gather information about textile sector current situation in Brazil, its impacts, sustainable design actions, denim `s production, technologies and future perspectives.

\footnotetext{
${ }^{2}$ https://www.terra.com.br/noticias/dino/colecao-de-inverno-2018-vicunha-e-nilit-se-unem-para-a-criacao-de-tecidosfuncionais,4a4d401517132862a130057d761c7745ywt72fyn.html
} 
Key-words:

Design; environment; textile waste; denim; production clean, sustainable production

\section{Referências Bibliográficas}

ABDI - Agência Brasileira de Desenvolvimento Industrial. Estudo prospectivo setorial: têxtil e confecção. Série Cadernos da Indústria. Brasília, v. 8, p. 1-180. 2010.

ABIT - Associação Brasileira da Indústria Têxtil e de Confeç̧ão. Têxtil e Confecção: Inovar, desenvolver e Sustentar, 2012.

ABIT - ASSOCIAÇÃO BRASILEIRA DA INDÚSTRIA TÊXTIL E DE CONFECÇÃO. Dados gerais do setor atualizados em 2016, referentes ao ano de 2015. Disponível em: http://www.abit.org.br. Acesso em: 12 jun. 2017.

ALMEIDA, C. M. V. B.; GIANNETTI, B. F. Ecologia Industrial Conceitos, ferramentas e aplicações. São Paulo: Ed. Edgard Blucher, 2009.

ALVAREZ, C. O impacto ambiental de uma camisa de algodão. Antena Paranóica de 2011. Disponível em https://novomundonovo.wordpress.com/2011/05/26/artigo-o-impacto-ambiental-de-uma-camisade-algodao/ Acesso em 18 jun. 2017.

ARAÚJO, E. S.; HIDALGA, V.; GIANNETI, B. F.; ALMEIDA, C. M. V. B. Ecologia Industrial: um Pouco de História. Disponível em <http://www.hottopos.com/regeq12/art2.htm> Acesso em: 18 jun. 2017.

BEST, K. Design Management: Managing Design Strategy, Process and Implementation. An AVA Book Academia, Switzerland, 2006.

CCP - Camara di Commercio Prato. Cardato Regenerated CO2 Neutral. Disponível em: http://www.po.camcom.it/news/comunica/2009/20090909.htm. Acesso em 13 jun. 2017.

CONAMA - Conselho Nacional de Meio Ambiente. Resolução nº 01 de 1986.

COULTURE MAGAZINE. Reduce-reuse-recycle: the clothing edition. Disponível em: http://www.coulture.org/fashion/2016/4/12/reduce-reuse-recycle-the-clothing-edition-1. Acesso em 13 jun. 2017.

DEBASTIANI, E. L.; MACHADO, L. A. Estudo sobre a geração de resíduos sólidos nas indústrias de confecção têxtil no município de Erechim-RS. In: $3^{\circ}$ Congresso Internacional de Tecnologias para o Meio Ambiente, Bento Gonçalves/RS, 25 a 27 de abril de 2012.

EL-HAGGAR, S. Sustainable industrial design and waste management. Oxford: Elsevier, 2007.

EPE - Empresa de Pesquisa energética -Balanço Energético Nacional, 2010: Ano-base 2009. Rio de Janeiro, 2010.

FIgUeIRedO, G. C.; CAVALCANTE, A. L. B. L. Calça Jeans - Produtividade e Possibilidades Sustentáveis. Projética, V. 1, N.1, P. 128-145, Londrina, 2010.

FOLADORI, G. A reedição capitalista das crises ambientais. Revista Outubro, v. 1, n. 17, p. 191-207, 2008.

IEMI - Instituto de Estudos e Marketing Industrial. Relatório Setorial da Indústria Têxtil Brasileira Brasil Têxtil 2015. 15a edição. São Paulo, 2015.

ITMF - International Textile Manufactures Federation. World Textile Summit 2011. Disponível em < http://www.worldtextilesummit.com/> Acesso em 18 jun. 2017.

KRUCKEN, L. TRUSEN, C. A comunicação da sustentabilidade de produtos e serviços. Cadernos de Estudos Avançados em Design. Editora EdUEMG, Barbacena, 2a edição, 2013.

LEITE, P. R. Logística reversa: meio ambiente e competitividade. São Paulo: Ed. Prentice-Hall, 2003. 
MANZINI, E.; VEZZOLI, C. O Desenvolvimento de Produtos Sustentáveis: Os requisitos ambientais dos produtos industriais. Tradução de Astrid de Carvalho. São Paulo: Edusp - Editora da Universidade de São Paulo, 2008. ISBN: 978-85-314-0731-4.

MASSOTE, C. H. R. Implementação da metodologia da produção mais limpa em uma indústria moveleira da região metropolitana de Belo Horizonte. Dissertação de Mestrado - Universidade Federal de Ouro Preto. Núcleo de Pesquisas e Pós-graduação em Engenharia Ambiental. 2010.

MORAN, C.; HALL, M. E.; HOWELL, R., Effects of Sewage Treatment on Textile Effluent. Journal of the Society of Dyers and Colourists, 113, p. 272-274, 1997.

MUHAMMAD, I. German Textile Recycling Benchmarking. Bachelor's thesis (Supply Chain Management). HAMK - University of Applied Sciences. Forssa, 2013.

OLIVEIRA, O. J; SERRA, J. R. Benefícios e dificuldades da gestão ambiental com base na ISO 14001 em empresas industriais de São Paulo. Revista Produção, v. 20, n. 3, p. 429-438, 2010.

ROCHA, F. As três regras de ouro da evolução da sustentabilidade nas organizações. Ciência e Tecnologia. EcoDesenvolvimento.org: Sustentabilidade, Meio Ambiente, Economia, Sociedade e Mudanças Climáticas, Redação Ecod, 2014.

SANCHES, A.G.O.; LUCATO, W.C.; VIEIRA JUNIOR, M. Tecendo Oportunidades: Competitividade na Fabricação de Denim. XII SEGeT. Simpósio Excelência em Gestão e Tecnologia. Otimização de recursos e Desenvolvimento. Resende - Rio de Janeiro, Out 2015.

SILVA, A. S. F. Avaliação de práticas e performance da manufatura enxuta, via benchmarking, para diagnóstico da indústria de confecções. 2009. Tese (Doutorado em Eng. de Produção). Escola de Eng. de Produção da Universidade Federal de Santa Catarina. Florianópolis, 2009.

SINDFIATEC - Sindicato de Fiação e Tecelagem em Geral - Campinas e região. Apresentado mapeamento inédito do setor têxtil em São Paulo. Disponível em <http://www.sindfiatec.com.br/home/index.php?option=com_content\&view=article\&id=111:apresent ado-mapeamento-inedito-do-setor-textil-em-saopaulo\&catid=21: noticias\&Itemid=165> Acesso em 12 jun. 2017.

SINDITÊXTIL - Sindicato das Indústrias de Fiação e Tecelagem do Estado de São Paulo. Retalho Fashion - Projeto de reciclagem une meio ambiente e inclusão social. Ano VII, n. 25, Jun de 2017. Disponível em < http://sinditextilsp.org.br/retalho_fashion/site/apresentacao.pdf >

SOUZA, P. A. F. Estética da Salvação X Estética da Perdição - Um Estudo Sobre Sustentabilidade na Indústria da Moda. E-tec, v. 1, n. 1, nov. 2008.

TALARPOSHTI, A.; DONNELLY, T.; ANDERSON, G. K., Colour Removal from a Simulated Dye Wastewater using a Twophse Anaerobic Packed Bed Reactor. Water Research, 35, p. 425-432, 2001.

TAVARES M.; ARNT R. Velha, azul, desbotada... e poluente: com certeza há um par de jeans no seu armário. Revista Meio Ambiente. Nº Edição: 462, 2011.

TECHNOPAK - New Challenges in the Fashion System - July 2014. IAF - International Appareal ederation. Nova Delhi: Technopak Adivirsors Pvt. Ltda, 2014. 27 p.

WASTE ON LINE. Textile recycling information sheet. Disponível em < http://www.smartasn.org/educators-kids/textile_recycling_fact_sheet.pdf > Acesso em 19 jun. 2017. 